\title{
E Cape health officials nearly turn TB victims into cash cows
}

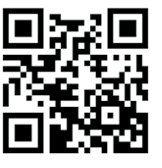

Only intervention by the Treatment Action Campaign (TAC) prevented thousands of unsuspecting TB sufferers from being used as human guinea pigs in a lucrative and potentially dangerous experiment.

Government and top health officials in the province were on the verge of rolling out an untested and unapproved 'immuneboosting remedy' to all local TB hospitals in what appears to be a cynical, predatory scheme that would have raked in millions for a natural health products company. This came after at least a dozen patients at primary healthcare clinics were illegally put on the unregistered and unapproved drug upon being falsely reassured that it was an approved 'pilot' scheme.

Early this March, inspectors from the Medicines Control Council (MCC) swooped on various provincial health offices and private premises in and around
Port Elizabeth, effectively impounding a R1.4 million consignment of the bovine colostrum-based Immutides Spray. Its distributors and a local district health clinician had punted it to the bewildered clinical chiefs of three TB hospitals, who were summoned to Port Elizabeth to hear about its alleged immune-boosting properties in a suspect trial done on a small number of HIV-positive patients in Nigeria. Izindaba sources said a Dr Francois Fourie, in charge of primary healthcare clinics in the region, appeared to know 'more about the product than the two guys from the marketing company' suggesting that the TB hospital chiefs use unspent money from their pharmacy budgets to purchase stocks of the unapproved 'medication'. The chief of one hospital was told that he should buy enough to roll it out for 6 months and the other two (one of whose hospital deals exclusively with multidrug-resistant TB patients) for 2 years.

\section{MCC turned down spray,} citing 'safety concerns'

Immutides had been evaluated and turned down because of 'genuine safety concerns' by two national MCC committees (one for veterinary products and the other for complementary medicines). The so-called 'immune-booster' remedy has been discredited as having no therapeutic value. The scam is the latest in a long history of corrupt practices and inept management involving top politicians and senior management in the EC - with national government until now seemingly powerless to intervene effectively. For the third year in succession, not a single provincial department received a clean audit, with local Standing Committee on Public Accounts (SCOPA) Chairperson, Max Mhlati, declaring this March, 'there are no consequences for non-compliance,' which he says is crippling the administration. $\mathrm{He}$ baldly told his legislature, 'the budget is 
there, but the people involved in corruption are here today to see where they're going to get a cut out of this budget'.

The directors of Saulez Agencies CC, which supplies the suspect spray, include Mr Mike Xego, a former Member of the Provincial Legislature and former ANC Chief of the Nelson Mandela Bay region. The criminal investigation, in terms of the Medicines Act and the Public Service Act, centres on an official directive sent out to the three provincial $\mathrm{TB}$ hospitals in the Nelson Mandela Bay region by Dr Lulekwa Mayekiso, a relatively junior doctor with little administrative experience, recently parachuted into the influential position of District Health Manager. She is the daughter of Dr Elizabeth Mamisa Chabula-Nxiweni, Chief Operating Officer for the Nelson Mandela Metro and its former Executive Director of Health (for greater Port Elizabeth).

Mayekiso's predecessor, Dr Tommy Oliver, resigned over a series of senior management directives 'inappropriate to his budget', and has since emigrated. His post was advertised at least three times over 18 months with several applicants being rejected. Once in the job, Mayekiso attached now-discredited documentation purporting to give official 'approval' for the TB spray to a directive to all senior managers involved in caring for patients in the TB hospitals (all located in her district). In it she ordered them to dispense the spray to all patients for the duration of treatment - and to issue scripts for the spray upon hospital discharge. The order was to have taken effect from 1 March this year.

\section{Immutides had been evaluated and turned down because of 'genuine safety concerns' by two national Medicines Control Council committees (one for veterinary products and the other for complementary medicines). The so-called 'immune-booster' remedy has been discredited as having no therapeutic value.}

\section{TAC tipped off and acted - just in time}

Just weeks before, the TAC got wind of the scheme and sent an urgent letter to the Provincial and National Directors General of Health, Dr Thobile Mbengashe and Precious Matsoso, resulting in those officials intimately involved protesting that 'nothing

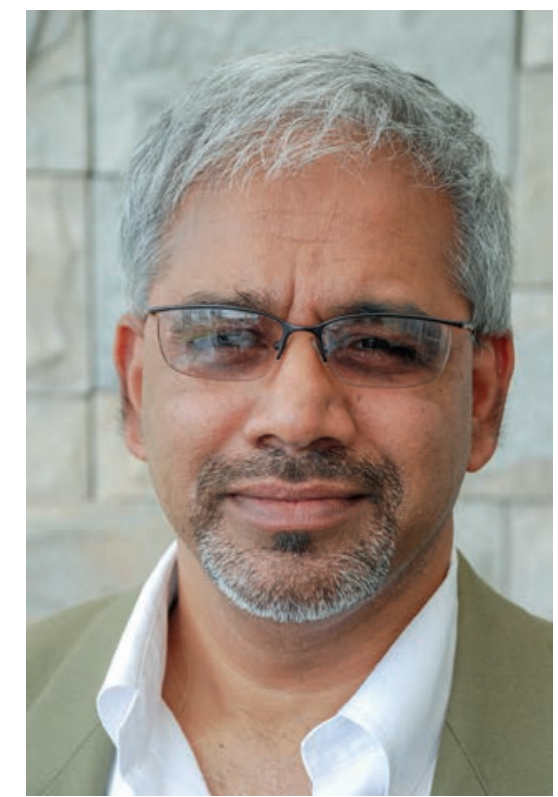

Former Eastern Cape Health Chief, Dr Siva Pillay. Picture: Chris Bateman.

actually happened' and denying any patient was put on the drug on their watch. The rollout directive, a copy of which is in Izindaba's possession, was addressed to the three TB hospital chiefs, the regional drug depot manager, the Nelson Mandela Bay Health District (NMBHD)'s senior clinical manager, its deputy directors for $\mathrm{TB}$ management and clinical support services, as well as the district pharmacist.

Bewildered NMBHD TB chiefs questioned the missive, which also orders a 6-month 'research project' (from 1 March) to evaluate the effect of the spray when added to the treatment regimen of TB patients. Mayekiso's missive asks for a final written report by the end of October, which she says will be 'evaluated by the NMBHD's top management, for future use of the Immutides Spray'. She asks her underlings to 'please note' that the initiation of the remedy 'will continue during the compiling and evaluation of the research report,' and concludes, 'it is with great excitement that I give this directive to investigate every means to [sic] our disposal to facilitate better outcomes for our TB patients. I would like to thank all stakeholders who will be involved in this project in advance, and may God bless our effort'

\section{Shadowy practices at top level}

According to Izindaba sources, the doctors who questioned the roll-out were told that if they wanted to work in the region, 'they need to learn to accept directives'. Some years ago Xego approached Dr Siva
Pillay, while he [Pillay] was the provincial Director General of Health in an initial bid to seek approval for an Immutides roll-out. When approached by Izindaba for comment, Pillay said 'I told him he had to go through the proper channels and obtain the right approvals before it was given to any patients ... that international norms and standards must be followed'.

Xego is understood to have then approached the Health MEC, Sicelo Qobana (with whom Pillay had a long-standing feud over healthcare delivery and suspect departmental practices). Sicelo's response was apparently that 'black business people are being frustrated'. Subsequently Mrs Nomalanga Makwedini, the province's then Acting Deputy Director General for Clinical Management Services, issued an official document, dated 20 March 2012, whose subject line reads 'Acknowledgement of approval - Immutides Spray'. In it she 'confirms' that 'Saulez Agencies CC applied to the $\mathrm{NDoH}$ [National Department of Health] for approval to register and supply Immutides Spray as a complementary medicine'. She then says that according to documents received from the $\mathrm{NDoH}$ [which were attached to the communique] 'permission has been granted for Immutides Spray to be imported and sold as complimentary medicine in accordance with Government Gazette Notice 23128'. This was in spite of two MCC committees and her provincial Therapeutics Committee having rejected the remedy.

\section{Fraudulent document}

Shown copies of the document emanating from his $\mathrm{NDoH}$ office which purports to give approval for the importation and selling of the spray (as a complementary medicine), Mr Griffith Molewa, Director General of the Inspectorate of Law Enforcement in the Pharmaceutical and Related Product Regulation Management Unit, said it did no such thing. He said Saulez Agencies submitted an application in terms of legislation aimed at quantifying what types of complementary medicines there were on the South African market, and permission to release their drug shipment from the port health authorities. 'That doesn't give them the right to sell or distribute - it just saves them harbour storage costs and enables them to put it into quarantine. The only body that can make any such pronouncement is the MCC - and that's only after you've provided data substantiated by a clinical trial for which you must register with the MCC. He said the legislation cited in the 
documents attached to Mayekiso's directive was rendered obsolete by a law introduced in November last year. Called an MDR 20.8 , the newly required approval gives a timetable of when to register products. 'The second (provincial) document you quote as giving acknowledgement of approval is simply wrong,' he added.

Quackdown, an internet database maintained by Section 27, lists Immutides as 'untested and implausible,' labelling it as an untested treatment for HIV and claiming that, 'disturbingly', a local distributor introduced it to four orphanages in the EC in 2012. ${ }^{[1]}$ An internet search reveals the spray to be manufactured by US-based MicroBasics and imported by Mark KaneBerman, a director of MicroBasics Africa and NutriBasics, leading local suppliers of animal-feed additives based in Standerton. ${ }^{[2]}$

The TAC's letter of complaint says any documentation suggesting that it was found safe and effective by the MCC was 'a gross misrepresentation of the facts'. An exhaustive search on the US National Institutes of Health's PubMed database returned no results for clinical trials conducted on human beings using bovine colostrum. Neither is there any evidence of any clinical trials published in reputable scientific journals supporting the use of this product in human beings with HIV or TB. Besides not having ethical or MCC approval, using an unregistered product on TB patients in the public sector is unlawful and unethical. The TAC said it doubted whether any targeted patients (research subjects or not) would be given the opportunity for informed consent. In its letter to the two health ministers, the organisation urges them to stop the project immediately to safeguard patients, to probe why the directive was issued and whether Dr Mayekiso is suitable to head the NMBHD. Requesting copies of all documentation relating to the EC Department of Health's purchase of Immutides, the TAC said it viewed the acquisition as irrational and potentially in contravention of the Public Finance Management Act'.

National Director General of Health, Precious Matsoso, told Izindaba that Mayekiso's directive was in contravention

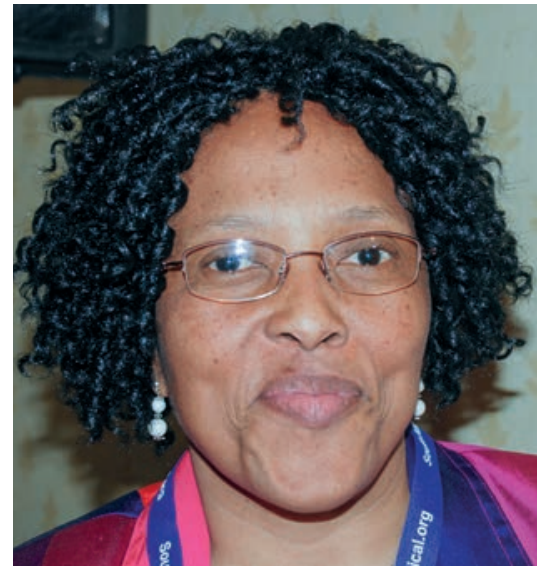

Precious Matsoso, former MCC Chief and current National Director General of Health. Picture: Chris Bateman.

of both the Medicines Act and the Public Service Act. 'We are requesting records from individuals involved - they broke the law, I can tell you that upfront. It is clear some strange things have been happening.' She said her MCC team was gathering evidence and criminal charges would follow. The $\mathrm{NDoH}$ document attached to Mayekiso's directive saying Immutides 'may be imported and sold as complimentary medicine in South Africa', was suspect and the national (law enforcement) official involved would be questioned, she added. 'Inspectors don't issue authorisations - the product had already been rejected so she had no authority whatsoever to issue that letter' Matsoso said. On the narrowly averted drug roll-out and 'pilot', she said, 'as clinical people we can't do that on human subjects without an ethics panel or MCC approval of the trial protocol. The MCC says it's an unregistered medicine. They also undermined the procurement process. We never called for tenders for that. How did they come about buying it? I say it was fraudulent.'

\section{Spray cost more per} patient than AIDS drugs

Izindaba sources said provincial officials 'insisted' the remedy was MCC-registered. One clinician officially pressured during the attempted roll-out commented, 'the spray would have cost more per patient dosage than what it costs monthly for the equivalent [antiretrovirals] ARVs - they were targeting the most vulnerable patients lying in TB hospitals, the sickest of the sick. It's just shocking.' Ironically, Mike Xego, who was present during at least one of the presentations to the TB hospital chiefs, has since threatened to sue the $\mathrm{NDoH}$ for 'stringing him along' ('leading' him to believe) he could distribute his company's product. Matsoso retorted, 'he's welcome to go ahead and sue us. We have a duty and a responsibility to protect the public.'

One EC clinician who spoke to Izindaba off the record, said using bovine colostrum without pasteurisation ran the risk of re-introducing bovine $\mathrm{TB}$ into the population via nosocomial (hospital) infections. Alternatively, pasteurising it meant all antibodies contained in the milk were rendered ineffective. 'I'm not familiar with their manufacturing process but I do know that much,' he said.

'They were targeting the most vulnerable patients lying in TB hospitals, the sickest of the sick.' senior clinician.

Veteran and trustworthy Izindaba sources in the EC Department of Health said that if the probe simply 'scapegoated' a few individual officials in the National and Provincial Departments of Health it would 'simply be papering over the cracks'. 'This thing leads directly to Bhisho head office where the authority was initially falsified and manipulated - senior heads must roll,' one added.

\section{Chris Bateman \\ chrisb@hmpg.co.za}

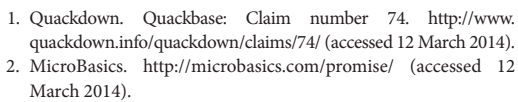
MicroBasics. http./microbacs.com/promise/ (ach 2014). March 2014)

S Afr Med J 2014;104(4):265-267. DOI:10.7196/SAMJ.8171 